\begin{tabular}{|c|c|c|c|}
\hline Case Reports in & \multicolumn{2}{|c|}{ Case Rep Gastroenterol 2018;12:715-721 } & \multirow[b]{2}{*}{$\begin{array}{l}\text { Karger } \\
\text { Open access }\end{array}$} \\
\hline Gastroenterology & $\begin{array}{l}\text { DOI: } 10.1159 / 000495246 \\
\text { Published online: November 28, } 2018\end{array}$ & $\begin{array}{l}\text { (c) } 2018 \text { The Author(s) } \\
\text { Published by S. Karger AG, Basel } \\
\text { www.karger.com/crg }\end{array}$ & \\
\hline & $\begin{array}{l}\text { This article is licensed under the } \mathrm{C} \\
\text { International License (CC BY-NC) (h } \\
\text { Usage and distribution for commercial }\end{array}$ & $\begin{array}{l}\text { nons Attribution-NonCommerci } \\
\text { ger.com/Services/OpenAccessLic } \\
\text { uires written permission. }\end{array}$ & \\
\hline
\end{tabular}

\title{
Collision Tumor of Adenocarcinoma and Gastrointestinal Stromal Tumor in the Small Bowel
}

\author{
Hitoshi Saito ${ }^{a, b}$ Yoshiaki Osaka ${ }^{a, b} \quad$ Kazuhiko Tamura ${ }^{a, b}$ \\ Hideaki Kawakita ${ }^{a, b} \quad$ Nao Kobayashi, ${ }^{a}$ Yuichi Nagakawa ${ }^{b}$ \\ Kenji Katsumatab ${ }^{b}$ Akihiko Tsuchida ${ }^{b}$ \\ aDepartment of Gastrointestinal and General Surgery, Kosei Chuo General Hospital, \\ Tokyo, Japan; bepartment of Gastrointestinal and Pediatric Surgery, Tokyo Medical \\ University Hospital, Tokyo, Japan
}

\section{Keywords}

Adenocarcinoma · Collision tumor - Gastrointestinal stromal tumor - Small bowel

\begin{abstract}
We report a very rare case of collision tumor composed of primary adenocarcinoma of the jejunum and gastrointestinal stromal tumor (GIST). The patient was a 63-year-old man who visited our hospital for epigastralgia and vomiting. Abdominal computed tomography revealed a mass in the upper jejunum, with gastric and duodenal dilatation. Endoscopy of the small bowel showed a circumferential tumor in the upper jejunum, which was diagnosed as primary adenocarcinoma by tissue biopsy. Thereafter, partial resection of the small bowel from the third part of the duodenum over the upper jejunum was performed. A tumor colliding with the primary adenocarcinoma was identified on the serosal side of the jejunum in the excised specimen and was histologically diagnosed as GIST. The annual incidence of primary adenocarcinoma of the small bowel (i.e., jejunum and ileum excluding the duodenum) has been reported to be 7 in 1 million people, and only 6 cases of collision tumor of the small bowel (i.e., duodenum: 5, ileum: 1) have been reported thus far. Although esophageal, gastric, and large intestinal collision tumors composed of primary cancer and GIST have been reported, to our knowledge, the present patient is the first case of the small bowel. The cause of or correlation between 2 tumors forming a collision tumor remains unclear. In the present patient, there was
\end{abstract}

KARGER
Hitoshi Saito, MD, PhD

Department of Gastrointestinal and General Surgery, Kosei Chuo General Hospital

1-11-7 Mita, Meguro-ku

Tokyo 153-8581 (Japan)

E-Mail hsaito_md_1964@yahoo.co.jp 


\section{Case Reports in Gastroenterology}

Case Rep Gastroenterol 2018;12:715-721

DOI: $10.1159 / 000495246$

(c) 2018 The Author(s). Published by S. Karger AG, Basel www.karger.com/crg

Saito et al.: Collision Tumor of Adenocarcinoma and Gastrointestinal Stromal Tumor in the Small Bowel

no pathological finding of infiltration between the 2 tumors. Although the collision of the 2 tumors was unclear, the findings indicate their independent development in closely located regions consistent with collision tumors.

(C) 2018 The Author(s)

Published by S. Karger AG, Basel

\section{Introduction}

Primary adenocarcinoma of the small bowel (i.e., jejunum and ileum excluding the duodenum) was detected in 2,123 people from 1992 to 2010 in the USA [1]. An analysis of these cases in a large-scale study clarified that the annual incidence was 7 in 1 million people, being a very rare pathology. Many cases are usually in the advanced stage at the time of detection, and the 5-year survival rate was reported to be $34.9 \%$. Surgery was the most effective treatment reported. Postoperative adjuvant chemotherapy failed to extend survival time but instead shortened it [1].

On the other hand, the incidence of gastrointestinal stromal tumors (GISTs) was reported to be the second highest in the small bowel following the stomach, and $89.8 \%$ of affected patients underwent surgery, with a 5-year survival rate of $82.2 \%$ [2]. A collision tumor composed of primary cancer and GIST in the same intestinal region is a very rare pathology. There has been apparently no case reported in the small bowel but only in the esophageal [3], gastric [4-6], and large intestinal [7] regions.

Regarding a collision tumor in the small bowel, only 5 duodenal cases [8] and 1 ileal case [9] have been described, and no jejunal case has been reported. Herein, we describe a very rare case of collision tumor of the small bowel composed of primary adenocarcinoma and GIST.

\section{Case Report}

\section{Clinical Presentation}

The patient was a 63-year-old man. His weight started to decrease by $10 \mathrm{~kg}$ from $60 \mathrm{~kg}$ within 3 months before being seen, and epigastralgia developed 1 month earlier. He was initially treated with an $\mathrm{H} 2$ antagonist when he visited a physician. Although this temporarily improved his symptoms, nausea and vomiting developed 2 weeks earlier, resulting in his admission to our hospital.

On admission, his temperature was $36.7^{\circ} \mathrm{C}$, his heart rate was 125 beats/min, his respiratory rate was 18 breaths/min, and his blood pressure was 83/67 mm Hg. His abdomen was soft and showed no tenderness. The abdominal mass lesion could not be palpated. His blood tests showed the following results: white blood cells, $12.1 \times 10^{3}$ (normal: $3.2-8.5 \times 10^{3}$ ); segmented neutrophils, 79.5\% (normal: 36.7-73.1\%); segmented lymphocytes, $13.3 \%$ (normal: 19.7-55.1\%); red blood cells, $514 \times 10^{3}$ (normal: 400-539 $\times 10^{3}$ ); hemoglobin, $16.9 \mathrm{~g} / \mathrm{dL}$ (normal: $13.0-16.6 \mathrm{~g} / \mathrm{dL}$ ); platelet count, $304 \times 10^{3}$ (normal: $130-349 \times 10^{3}$ ); total serum protein $7.9 \mathrm{~g} / \mathrm{dL}$ (normal: $6.5-8.0 \mathrm{~g} / \mathrm{dL}$ ); serum albumin $5.0 \mathrm{~g} / \mathrm{dL}$ (normal: $4.0-5.3 \mathrm{~g} / \mathrm{dL}$ ); total serum bilirubin $1.2 \mathrm{mg} / \mathrm{dL}$ (normal: 0.0-1.2 mg/dL); aspartate aminotransferase, $25 \mathrm{IU} / \mathrm{L}$ (normal: 8-35 IU/L); alanine aminotransferase, $36 \mathrm{IU} / \mathrm{L}$ (normal: 6-35 IU/L); alkaline phosphatase, $271 \mathrm{IU} / \mathrm{L}$ (normal: 104-338 IU/L); lactate dehydrogenase, 190 IU/L (normal: 106-211 IU/L); blood urea nitrogen, $42.7 \mathrm{mg} / \mathrm{dL}$ (normal: $7.0-21.0 \mathrm{mg} / \mathrm{dL}$ ); creatinine, $2.66 \mathrm{mg} / \mathrm{dL}$ (normal: $0.60-1.10 \mathrm{mg} / \mathrm{dL}$ ); serum carcinoembryonic antigen, $1.6 \mathrm{ng} / \mathrm{mL}$ (normal: $0.0-4.9 \mathrm{ng} / \mathrm{mL}$ ); 
serum carbohydrate antigen 19-9, $30.7 \mathrm{U} / \mathrm{mL}$ (normal: 0.0-36.9 U/mL); and serum alpha fetoprotein, $2.3 \mathrm{ng} / \mathrm{mL}$ (normal: $0.0-9.9 \mathrm{ng} / \mathrm{mL}$ ).

Chest radiography showed no findings suggesting metastasis. Abdominal computed tomography also showed no findings suggesting metastasis to other organs. However, a tumor was found in the upper jejunum, with accompanying gastric and duodenal dilation (Fig. 1a, b).

Endoscopy of the small bowel revealed a hemorrhagic tumor accompanied by circumferential stenosis in the upper jejunum (Fig. 1c). This tumor was diagnosed as well-differentiated adenocarcinoma by tissue biopsy.

Based on his clinical findings, the patient's condition was diagnosed as primary adenocarcinoma of the small bowel accompanied by stenosis. Partial resection of the small bowel including the third and fourth parts of the duodenum and upper jejunum, and side-to-side anastomosis between the second part of the duodenum and residual jejunum were performed. The postoperative course was favorable, and the patient was discharged after 3 weeks. Capecitabine was administered as postoperative adjuvant chemotherapy for 6 months. The patient has no sign of recurrence 5 years after the surgery.

\section{Pathological Findings}

The excised specimen (Fig. 2a) was a part of the small bowel composed of the third part of the duodenum over the jejunum down to about $18 \mathrm{~cm}$ on the anal side of the tumor. A $40 \times$ $29 \mathrm{~mm}$ tumor accompanied by thickening of the wall and ulceration was identified in the upper jejunum, and another $24 \times 21 \mathrm{~mm}$ tumor externally protruding from the intestinal wall was present on the dorsal side of the jejunal tumor (Fig. 2b, c).

Histologically, the main lesion was a well-differentiated to moderately differentiated adenocarcinoma infiltrating the subserosal layer (Fig. 3a). It was accompanied by venous invasion with metastasis to the intestinal mural lymph node. The resected stump was negative for cancer, and the histological stage was IIIA.

The other tumor was present in the subserosal layer colliding with the main lesion (Fig. 3b). Histologically, the tumor consisted of spindle cells and the tumor cells were immunohistochemically positive for CD117 (Fig. 3c) and CD34. Regarding the number of nuclear divisions, the Mib-1 index was 5\%, being a low-risk GIST.

Based on his pathological findings, the patient's condition was diagnosed as collision tumor of the small bowel composed of primary adenocarcinoma and GIST.

\section{Discussion}

In the USA, there were 2,123 patients with primary adenocarcinoma of the small bowel excluding the duodenum between 1992 and 2002, with an annual incidence of 7 in 1 million people [1]. The histological type of the tumor was poorly differentiated or undifferentiated in $28.6 \%$ of the patients. Also, many patients had accompanying distant metastasis. Moreover, $35.6 \%$ of the patients were in stage IV, being advanced compared with colorectal cancer. For treatment, only surgery was effective and the outcome of patients in stages III and IV and who were receiving 5 -fluorouracil-based postoperative adjuvant chemotherapy was poor compared with that of patients treated with surgery alone. The 5-year survival rate of all the patients was only $34.9 \%$, and the outcome was poor compared with that of colorectal cancer patients [1]. In earlier studies on primary cancer of the small bowel including the duodenum, the stage was already advanced when it was discovered similarly to the findings of Young et al. [1], with a 5-year survival rate of $30 \%$ or lower $[10,11]$. In addition, postoperative adjuvant 


\section{Case Reports in Gastroenterology}

Case Rep Gastroenterol 2018;12:715-721

DOI: $10.1159 / 000495246$

c 2018 The Author(s). Published by S. Karger AG, Basel www.karger.com/crg

Saito et al.: Collision Tumor of Adenocarcinoma and Gastrointestinal Stromal Tumor in the Small Bowel

chemotherapy was necessary because of the advanced stage $[12,13]$, although its effect was unclear. As the stage of primary adenocarcinoma of the small bowel in the present patient was IIIA, postoperative adjuvant chemotherapy with capecitabine was performed following treatment of the colorectal cancer, as performed in previous cases. Five years after surgery, the patient is alive with no sign of recurrence. However, it is not completely clear whether the postoperative adjuvant chemotherapy was effective.

GIST develops because of the abnormal proliferation of interstitial cells of Cajal the muscular layer of the intestine. In terms of the frequency of digestive tract mesenchymal tumors, GIST has the highest frequency. For the developmental site in the digestive tract, the stomach accounts for $60 \%$, followed by the small bowel at 15-20\%, and then the large intestine, esophagus, and appendix. CD117 (C-kit) and CD34 are expressed in 50-80\% of cases, being differentiable from other tumors. Malignancy of the tumor is judged based on its size and mitotic index. In the present case, the size was $>20 \mathrm{~mm}$ but the mitotic index was $<5$, being a low-risk tumor. Thus, adjuvant chemotherapy was not considered. There was no sign of recurrence similarly to the primary adenocarcinoma of the small bowel.

Collision tumor is a rare pathology defined as morphologically different tumors originating in different regions but coalescing with each other in a particular area or colliding and partially invading each other [14]. Only 6 cases of collision tumor of the small bowel (duodenum: 5 cases [8], ileum: 1 case [9]) have been reported in Medline thus far. Regarding cancer and GIST in the same digestive tract region, gastric collision tumor is the most frequently reported [4-6]. Esophageal [3] and large intestinal [7] tumors have also been described. However, no small intestinal case has been reported, and the present patient is apparently the first case involving the duodenum and jejunum to be described. Regarding the simultaneous development of adenocarcinoma and GIST, a hypothesis has been proposed that gene mutation occurs or a single carcinogenic substance interacts with 2 adjacent tissues or that there is a possible development of different histological type tumors in the same organ. However, the presence or absence of a causal relationship with the development of each tumor remains unclear [15]. In the present patient, the adenocarcinoma and GIST came in contact with each other, but showed no invasion. Thus, it is possible that the 2 tumors developed at a site close to each other. It was unclear whether there was a correlation between the developments of the 2 tumors. As GIST of the small bowel is not a rare pathology, collision tumors involving GIST may become more frequently encountered in the future, for which their further elucidation is expected.

\section{Conclusion}

We describe a rare case of collision tumor of the small bowel composed of primary adenocarcinoma and GIST. Although the effect of postoperative adjuvant chemotherapy on the patient was not specifically clear, there was no recurrence 5 years after surgery. As collision tumor of the small bowel is a very rare pathology, this apparent first case of collision tumor composed of primary adenocarcinoma and GIST in the small bowel (duodenum, jejunum, and ileum) will additionally provide important clinical and pathological information on such a rare histological type. As the developmental origin and correlation between the 2 tumors were not definitively clear, additional cases must be continually examined to elucidate these aspects. 


\section{Statement of Ethics}

Written informed consent was obtained from the patient for publication of this case report and any accompanying images.

\section{Disclosure Statement}

All authors declare no conflicts of interest.

\section{References}

1 Young JI, Mongoue-Tchokote S, Wieghard N, Mori M, Vaccaro GM, Sheppard BC, et al. Treatment and survival of small-bowel adenocarcinoma in the United States: A comparison with colon cancer. Dis Colon Rectum. 2016 Apr;59(4):306-15.

2 Giuliano K, Nagarajan N, Canner J, Najafian A, Wolfgang C, Schneider E, et al. Gastric and small intestine gastrointestinal stromal tumors: do outcomes differ? J Surg Oncol. 2017 Mar;115(3):351-7.

3 Qian T, Gao F, Chen MZ, Meng FH, Li XJ, Liu YJ, et al. Collision tumor of the esophagus: report of a case with mixed squamous cell carcinoma and gastrointestinal stromal tumor. Int J Clin Exp Pathol. 2014 Feb;7(3):1206-11.

4 Idema DL, Daryanani D, Sterk LM, Klaase JM. Collision tumor of the stomach: a case of an adenocarcinoma and a gastrointestinal stromal tumor. Case Rep Gastroenterol. 2008 Sep;2(3):456-60.

5 Bi R, Sheng W, Wang J. Collision tumor of the stomach: gastric adenocarcinoma intermixed with gastrointestinal stromal tumor. Pathol Int. 2009 Dec;59(12):880-3.

6 Kleist B, Lasota J, Miettinen M. Gastrointestinal stromal tumor and gastric adenocarcinoma collision tumors. Hum Pathol. 2010 Jul;41(7):1034-9.

7 Kurosaka Y, Kiriyama M, Nishizima K, Itou H, Ii T, Takegawa S, et al. A case of cecal GIST collision with an advanced colon cancer. Nihon Daicho Komonbyo Gakkai Zasshi. 2004;57(2):61-5. Japanese.

8 Peng L, Schwarz RE. Collision tumor in form of primary adenocarcinoma and neuroendocrine carcinoma of the duodenum. Rare Tumors. 2012 Apr;4(2 e20):e20.

9 Van Kerkhóve F, Coenegrachts K, Steyaert L, Van Den Berghe I, Casselman JW. Collision tumor in the ileum: a rare combination of an adenocarcinoma and small cell neuroendocrine tumor. JBR-BTR. 2006 SepOct;89(5):258-60.

10 Bilimoria KY, Bentrem DJ, Wayne JD, Ko CY, Bennett CL, Talamonti MS. Small bowel cancer in the United States: changes in epidemiology, treatment, and survival over the last 20 years. Ann Surg. 2009 Jan;249(1):63-71.

11 Zouhairi ME, Venner A, Charabaty A, Pishvaian MJ. Small bowel adenocarcinoma. Curr Treat Options Oncol. 2008 Dec;9(4-6):388-99.

12 Wu TJ, Yeh CN, Chao TC, Jan YY, Chen MF. Prognostic factors of primary small bowel adenocarcinoma: univariate and multivariate analysis. World J Surg. 2006 Mar;30(3):391-8.

13 Dabaja BS, Suki D, Pro B, Bonnen M, Ajani J. Adenocarcinoma of the small bowel: presentation, prognostic factors, and outcome of 217 patients. Cancer. 2004 Aug;101(3):518-26.

14 Meyer R. Beitrag zur Verständigung über die Namengebung in der Geschwulstlehre. Zentralbl Allg Pathol. 1919;30:291-6.

15 Maiorana A, Fante R, Maria Cesinaro A, Adriana Fano R. Synchronous occurrence of epithelial and stromal tumors in the stomach: a report of 6 cases. Arch Pathol Lab Med. 2000 May;124(5):682-6. 

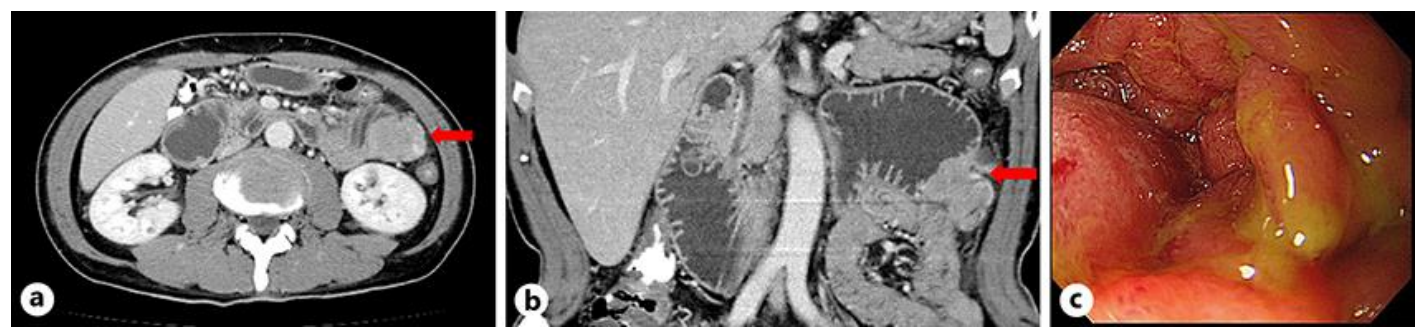

Fig. 1. Abdominal computed tomography revealed a mass with a poor contrast enhancement in the upper jejunum. The duodenum and stomach on the oral side of this region were dilated. There was no metastasis in other organs $(\mathbf{a}, \mathbf{b})$. Endoscopy of the small intestine showed a tumor with marginal swelling at about $5 \mathrm{~cm}$ on the anal side from Treitz' ligament which prevented passage of an endoscope (c).
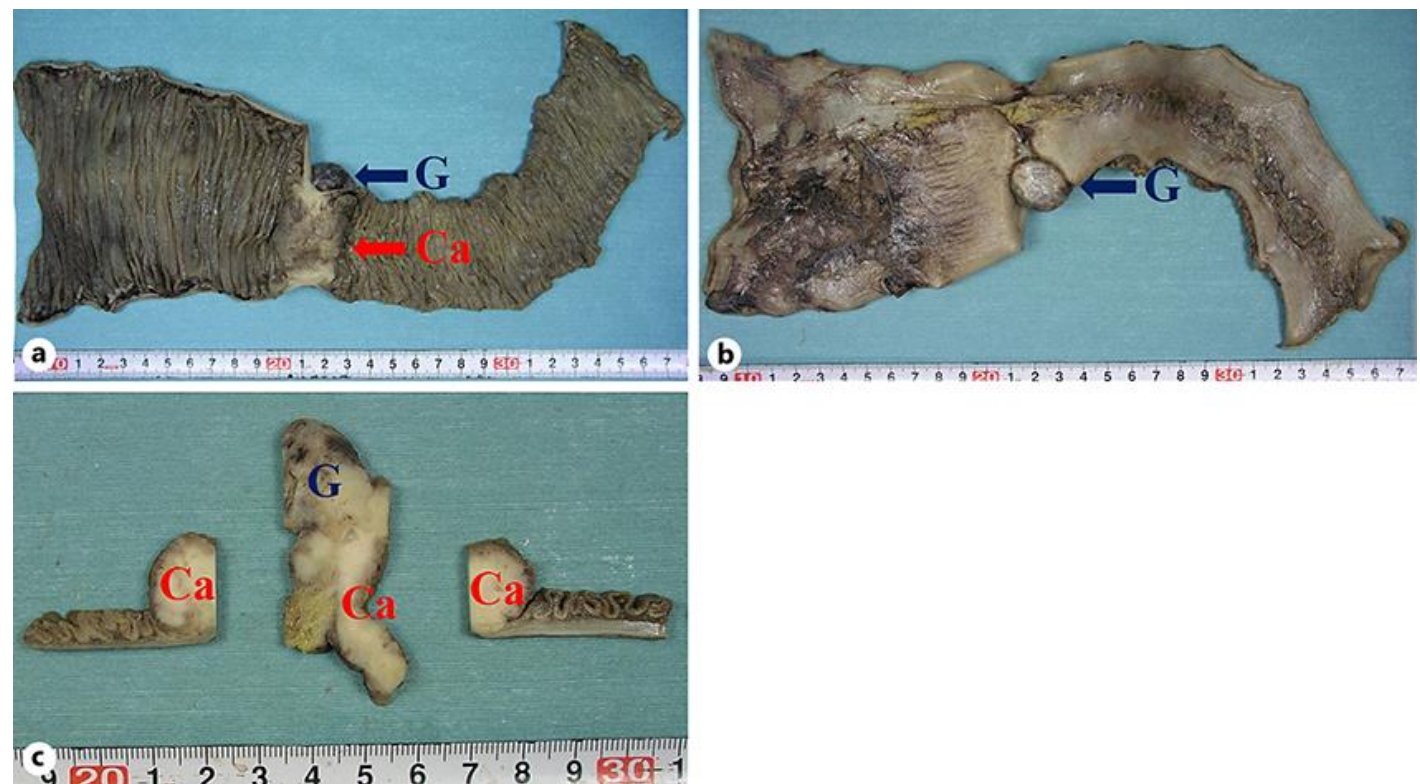

Fig. 2. The excised specimen was the horizontal portion of the duodenum over the jejunum down to about $18 \mathrm{~cm}$ on the anal side of the tumor. The size of the adenocarcinoma was $40 \times 29 \mathrm{~mm}$, and thickening of the wall and ulceration were noted (a). The size of the GIST was $24 \times 21 \mathrm{~mm}$ and the tumor externally protruded from the jejunum on the serosal surface (b). In the cross-section, the 2 tumors macroscopically collided (c). Ca, adenocarcinoma; G, GIST. 


\section{Gastroenterology} DOI: 10.1159/000495246

(c) 2018 The Author(s). Published by S. Karger AG, Basel www.karger.com/crg

Saito et al.: Collision Tumor of Adenocarcinoma and Gastrointestinal Stromal Tumor in the Small Bowel
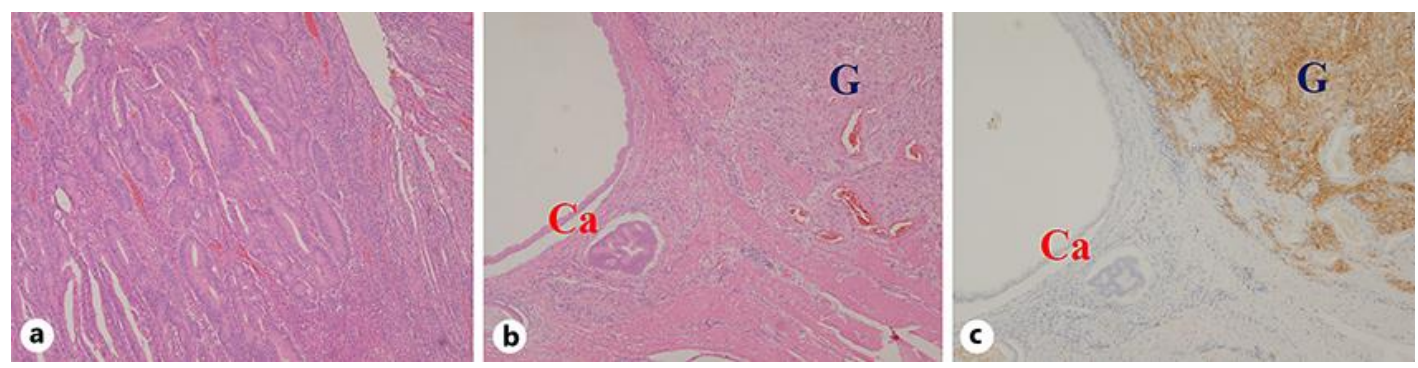

Fig. 3. The main lesion on HE staining was moderately differentiated adenocarcinoma $(\mathbf{a} \times 40)$. The advancing region of the adenocarcinoma invaded the subserosal layer with accompanying lymphocyte infiltration. Another tumor composed of spindle cells colliding with the main lesion was identified $(b \times 40)$. The other tumor showed positive CD117 staining $(\mathbf{c} \times 40)$ and strongly positive CD34 staining, based on which the tumor was diagnosed as GIST. Ca, adenocarcinoma; G, GIST. 